\title{
Augmentation of diabetes-associated renal hyperfiltration and nitric oxide production by pregnancy in rats
}

\author{
S Omer, J Shan, D R Varma ${ }^{1}$ and S Mulay
}

Departments of Physiology and Medicine, McGill University, and Cardiology Division, Royal Victoria Hospital, Montreal, Quebec, Canada H3A 1A1

${ }^{1}$ Department of Pharmacology and Therapeutics, McGill University, Montreal, Quebec, Canada H3G 1Y6

(Requests for offprints should be addressed to S Mulay, Cardiology Division, Royal Victoria Hospital, Room M4.76, 687 Pine Avenue West, Montreal, Quebec, Canada H3A 1A1)

\begin{abstract}
We tested the hypothesis that pregnancy might increase diabetes-associated nitric oxide (NO) production and renal hyperfiltration. Two weeks following i.v. streptozotocin $(40 \mathrm{mg} / \mathrm{kg})$, mean arterial pressure (MAP) was not modified by diabetes; glomerular filtration rate (GFR), renal plasma flow (RPF) and filtration fraction (FF) were higher in pregnant than in virgin controls and increased by diabetes to a greater extent in pregnant than in virgin rats. Urinary volume (UV), creatinine, albumin and sodium $\left(\mathrm{U}_{\mathrm{Na}} \mathrm{V}\right)$ were significantly increased by diabetes. Diabetes led to an increase in renal, cardiac, aortic and uterine but not in placental $\mathrm{NO}$ synthase activities. Infusion of $\mathrm{N}^{\mathrm{G}}$ nitro-L-arginine (L-NA) caused a dose-dependent reduction in GFR, RPF, plasma $\mathrm{NO}_{2}{ }^{-} / \mathrm{NO}_{3}{ }^{-}, \mathrm{UV}$ and
\end{abstract}

$\mathrm{U}_{\mathrm{Na}} \mathrm{V}$; in general, diabetes increased these effects to a greater extent in pregnant than in virgin rats. L-NA increased MAP in all groups of rats but did not alter FF. Diabetes did not alter responses of thoracic aorta rings to vasoconstrictor effects of phenylephrine and the vasorelaxant effects of sodium nitroprusside but increased endothelium-dependent relaxant effects of acetylcholine. In general the effects of diabetes of 7 days duration were similar to those described above for diabetes of 14 days duration. These data suggest that diabetes-associated renal hyperfiltration and NO production are augmented by pregnancy.

Journal of Endocrinology (1999) 161, 15-23

\section{Introduction}

Nephropathy is one of the serious long-term complications of diabetes and may develop in 30-40\% of diabetes mellitus patients (Rudberg et al. 1992, Chowdhury et al. 1996). Although several factors are involved in the genesis of diabetic nephropathy, glomerular hyperfiltration with increased intraglomerular pressure antedates the development of nephropathy and appears to contribute to the diabetes-associated renal injury (Hostetter et al. 1981, Chowdhury et al. 1996). Increased renal plasma flow (RPF) often accompanies diabetes mellitus (Chowdhury et al. 1996). Vascular endothelial nitric oxide (NO) plays a role in renal haemodynamics (Shultz et al. 1990, Raij 1993, Danielson \& Conrad 1995, Baylis \& Qiu 1996) and contributes to renal hyperfiltration during streptozotocin diabetes in rats (Bank \& Aynedjian 1993, Tolins et al. 1993, Komers et al. 1994).

The endothelium-dependent vasorelaxant effects of acetylcholine (ACh) (Furchgott \& Zawadzki 1980) and several other substances (Furchgott 1983) seem to be caused primarily by a release of NO (Palmer et al. 1987, Moncada et al. 1991). Diabetes can lead to endothelial dysfunction (Poston \& Taylor 1995, Sobrevia \& Mann
1997), which can alter NO homeostasis. Clinical data suggest that the role of $\mathrm{NO}$ is not uniform on different blood vessels and is influenced by the presence of different diabetic complications (Hicks et al. 1997, Veves et al. 1998); a variability and heterogeneity in endothelial NO functions in different blood vessels is also observed in experimental diabetes (Kiff et al. 1991).

$\mathrm{NO}$ is synthesized from the terminal guanidinonitrogen atom of the amino acid L-arginine; its synthesis is catalysed by NO synthase (NOS) and can be blocked by L-arginine analogues such as $\mathrm{N}^{\mathrm{G}}$-monomethyl-L-arginine (L-NMMA), $\mathrm{N}^{\mathrm{G}}$-nitro-L-arginine methyl ester (LNAME) and $\mathrm{N}^{\mathrm{G}}$-nitro-L-arginine (L-NA) (Moncada et al. 1991). Inhibition of NOS activity by different L-arginine analogues has been extensively utilized as a tool to assess the role of NO in modulating vascular tone (Poston \& Taylor 1995).

Pregnancy is associated with profound renal haemodynamic changes including a marked increase in glomerular filtration rate (GFR) both in humans (Gallery 1984) and rats (Baylis 1984), which might be contributed by NO (Danielson \& Conrad 1995). Diabetic complications are aggravated by pregnancy (Kitzmiller \& Combs 1996) but a contribution of $\mathrm{NO}$ in renal complications during 
diabetic pregnancy has not, to our knowledge, been reported. Here we tested the hypothesis that pregnancy might increase the role of $\mathrm{NO}$ in diabetes-associated renal hyperfiltration using virgin and pregnant rats as the model, 7 and 14-15 days after the induction of streptozotocin diabetes.

\section{Materials and Methods}

\section{Chemicals}

The following agents were purchased: inulin-methoxy [methoxy- ${ }^{3} \mathrm{H}$ ] $(500 \mathrm{mCi} / \mathrm{g})$ and $p$-aminohippuric acid (PAH) $\quad$ glycyl- $\left.1-{ }^{14} \mathrm{C}\right] \quad(60 \mathrm{Ci} / \mathrm{mmol})$ (NEN, Boston, MA, USA); $\left[{ }^{3} \mathrm{H}\right] \mathrm{L}$-arginine $(63 \mathrm{Ci} / \mathrm{mmol})$ (Amersham, Oakville, ON, Canada); L-NA, NADPH, nitrate reductase, calmodulin, tetrahydrobiopterin, Griess reagent, soybean trypsin inhibitor, aprotinin, L-valine, $\mathrm{NaNO}_{2}$, $\mathrm{NaNO}_{3}$, dithiothreitol, $\mathrm{ACh}$, phenylephrine and sodium nitroprusside (SNP) (Sigma Chemical Co., St Louis, MO, USA); all other high purity chemicals (BDH, Montreal, QC, Canada).

\section{Animals and induction of diabetes}

Experiments were done on Sprague-Dawley rats (Charles River, St Constant, QC, Canada) according to a protocol of the McGill University Animal Care Committee. Animals were housed at $22-24{ }^{\circ} \mathrm{C}, 55-70 \%$ humidity and a schedule of $12 \mathrm{~h}$ light: $12 \mathrm{~h}$ darkness (lights on 0700$1900 \mathrm{~h}$ ) and freely fed rat chow and tap water. Female rats weighing 200-225 g were housed with 250-275 g males overnight; the presence of sperm in the vaginal wash the following morning was designated as day 0 of pregnancy. Diabetes was induced by a single injection of streptozotocin $(40 \mathrm{mg} / \mathrm{kg})$ into the tail vein of rats on day zero of pregnancy and in age-matched virgin rats; controls were injected with the vehicle (citrate saline buffer, $\mathrm{pH} 4 \cdot 5$ ) (Conliffe et al. 1992). Urine was tested for the presence of glucose by Chemstrips (Boehringer Mannheim, Montreal, QC, Canada) for 2 successive days and animals which did not exhibit glucosuria were discarded. A small number of studies was done 7 days after the induction of diabetes; effects of 14-15 days duration of diabetes were studied in greater detail. Blood was collected from all animals at the time of killing and plasma glucose was determined by a CX-7 Beckman autoanalyser (Beckman, Palo Alto, CA, USA).

\section{Albumin and creatinine assays}

Urinary albumin was measured using a Nephrat rat albumin ELISA kit (Cedarlane, Hornby, ON, Canada). Briefly, standards and urine samples were incubated in microwells coated with anti-rat albumin for $20 \mathrm{~min}$ at room temperature followed by incubation with rat albumin-horseradish peroxidase conjugate for another $30 \mathrm{~min}$. Unbound reactants were removed by washing and the bound conjugate was reacted with tetramethylbenzidine substrate solution; the chromogenic reaction was stopped with dilute sulphuric acid and the colour intensity was determined using a microplate reader at $450 \mathrm{~nm}$.

Plasma and urinary creatinine were determined on a CX-7 autoanalyser; the assay is based on mixing the samples with alkaline picrate reagent and monitoring the rate of complex formation, which is directly proportional to creatinine concentration, bichromatically at 520 and $560 \mathrm{~nm}$.

\section{Renal haemodynamic studies}

Renal haemodynamic studies were done as previously described (Omer et al. 1995). Briefly, rats were anaesthetized by i.p. injection of $1 \mathrm{~g} / \mathrm{kg}$ urethane; no anaesthetic supplementation was required during the course of the experiment. Polyethylene catheters were inserted into the jugular vein for infusions and into the carotid artery for blood sampling and for monitoring the arterial pressure by means of a Statham pressure transducer (P23) on a Grass polygraph (Quincy, MA, USA). A catheter was placed into the urinary bladder for continuous urine collection. Following a $30 \mathrm{~min}$ period of stabilization after the completion of cannulations, a continuous i.v. infusion of $\left[{ }^{3} \mathrm{H}\right]$ inulin $(2 \mu \mathrm{Ci} / \mathrm{kg}$ per h$)$ and $\left[{ }^{14} \mathrm{C}\right] \mathrm{PAH}(2 \mu \mathrm{Ci} / \mathrm{kg}$ per h) was started at a rate of $1 \cdot 2 \mathrm{ml} / \mathrm{h}$. Following a $2 \mathrm{~h}$ period of equilibration, two $15 \mathrm{~min}$ urine samples were collected into pre-weighed Eppendorf tubes; control blood samples $(300 \mu \mathrm{l})$ were collected from the arterial cannula at the midpoint of each urine sampling; blood loss was replaced by an equivalent volume of physiological saline. Following these control sample collections, infusion of L-NA was started at $0.25 \mu \mathrm{mol} / \mathrm{kg}$ per min for $30 \mathrm{~min}$; a urine sample was collected corresponding to the last $15 \mathrm{~min}$ of L-NA infusion and a blood sample was collected at the midpoint of urine collection. This procedure was repeated at an L-NA infusion rate of $0.5 \mu \mathrm{mol} / \mathrm{kg}$ per min and then at $1 \mu \mathrm{mol} / \mathrm{kg}$ per min. Following the final blood collection, kidneys were removed and their weights recorded. Plasma and urine $\left[{ }^{3} \mathrm{H}\right]$ inulin and $\left[{ }^{14} \mathrm{C}\right] \mathrm{PAH}$ concentrations were determined by counting radioactivity on an LKB 1219 Rackbeta scintillation counter (Wallac, Turku, Finland); clearance of $\left[{ }^{3} \mathrm{H}\right]$ inulin and $\left[{ }^{14} \mathrm{C}\right] \mathrm{PAH}$ was calculated to determine GFR and RPF respectively (Bank \& Aynedjian 1993, Omer et al. 1995). Filtration fraction (FF) was calculated as a quotient of GFR and RPF. Urinary sodium was measured by an IL-443 flame photometer (ColeParmer, Vernon Hills, IL, USA) (Omer et al. 1995).

Plasma $\mathrm{NO}_{2}{ }^{-} / \mathrm{NO}_{3}{ }^{-}$

Plasma $\mathrm{NO}_{2}{ }^{-} / \mathrm{NO}_{3}{ }^{-}$was measured using the Griess reagent (Moshage et al. 1995, Verdon et al. 1995). Briefly, 
samples were incubated with nitrate reductase in the presence of NADPH to reduce all nitrate to nitrite. After the enzyme incubation, samples were treated with Griess reagent and quantified by measuring absorbance at $540 \mathrm{~nm}$ using a plate reader; known concentrations of $\mathrm{NaNO}_{2}$ and $\mathrm{NaNO}_{3}$ were utilized as standards in each assay. The NO measured in this way reflected the sum of $\mathrm{NO}_{2}{ }^{-}$and $\mathrm{NO}_{3}{ }^{-}$in the original sample.

\section{NOS activity}

In addition to animals used for haemodynamic studies, five or six rats from each group were anaesthetized with i.p. injections of $40 \mathrm{mg} / \mathrm{kg}$ sodium pentobarbitone. Blood was collected by means of cardiac puncture; kidneys, heart, aorta, placentas and uterus were removed, snap frozen in liquid nitrogen and stored at $-80^{\circ} \mathrm{C}$ for the assay of NOS activity. Tissue NOS activities were determined as previously described (Salter et al. 1991, Hardy et al. 1996). Briefly, tissues were homogenized by means of a Polytron (Brinkmann, Rexdale, Ontario, Canada) at setting 7 in a buffer containing $320 \mathrm{mM}$ sucrose, $50 \mathrm{mM}$ Tris- $\mathrm{HCl}$, $1 \mathrm{mM}$ dithiothreitol, $100 \mu \mathrm{g} / \mathrm{ml}$ polymethylsulphonyl fluoride, $10 \mu \mathrm{g} / \mathrm{ml}$ leupeptin, $100 \mu \mathrm{g} / \mathrm{ml}$ soybean trypsin inhibitor, $2 \mu \mathrm{g} / \mathrm{ml}$ aprotinin and $60 \mathrm{mM}$ L-valine, which was adjusted to $\mathrm{pH} 7 \cdot 4$ with $\mathrm{HCl}$. The homogenate was centrifuged at $12000 \mathrm{~g}$ for $20 \mathrm{~min}$ and the supernatant was used for the assay of NOS activity.

An aliquot of the supernatant $(35-75 \mu \mathrm{g}$ protein) was incubated in the absence or the presence of $2 \mathrm{mM} \mathrm{L}-\mathrm{NA}$ in $400 \mu \mathrm{l}$ assay buffer containing $50 \mathrm{mM}$ Hepes, $1 \mathrm{mM}$ dithiothreitol, $1.2 \mathrm{mM} \mathrm{MgCl}, 2 \mathrm{mM} \mathrm{CaCl}, 100 \mu \mathrm{M}$ $\left[{ }^{3} \mathrm{H}\right] \mathrm{L}$-arginine, $1 \mathrm{mM}$ NADPH, $15 \mu \mathrm{M}$ tetrahydrobiopterin, $1 \mu \mathrm{M}$ flavine adenine dinucleotide and $1 \mu \mathrm{M}$ calmodulin for $10 \mathrm{~min}$ at $37^{\circ} \mathrm{C}$ in a shaking water bath. The reaction was terminated by adding the following: $1 \mathrm{ml}$ ice-cold $100 \mathrm{mM}$ Hepes (pH 5.5) containing $10 \mathrm{mM}$ EGTA and 1.5 ml 1:1 $\mathrm{H}_{2}$ O:Dowex-50 (200-400, 8\% crosslinked, $\mathrm{Na}^{+}$form). The $\mathrm{Na}^{+}$form of Dowex-50 was prepared by washing four times the $\mathrm{H}^{+}$form of resin with $1 \mathrm{M} \mathrm{NaOH}$ and then washing with $\mathrm{H}_{2} \mathrm{O}$ until the $\mathrm{pH}$ was $<7.5$ (Salter et al. 1991, Hardy et al. 1996). The resin incubate mix was allowed to settle for $10 \mathrm{~min}$ and then centrifuged at $3500 \mathrm{~g}$ for $10 \mathrm{~min}$. The synthesis of $\left[{ }^{3} \mathrm{H}\right]$ citrulline was estimated by counting the radioactivity of the supernatant. Radioactivity in the presence of $10 \mathrm{mM}$ EGTA in the buffer yielded $\mathrm{Ca}^{2+}$-independent NOS activity. Total NOS activity was calculated as the L-NA-sensitive formation of $\left[{ }^{3} \mathrm{H}\right]$ citrulline and $\mathrm{Ca}^{2+}$ dependent NOS activity was the difference between the total NOS activity and that in the presence of EGTA. The effect of different concentrations of L-NA on NOS activity was determined in three separate experiments each in triplicate using rat cerebellum, which contains high NOS activity (Moncada et al. 1991); it was found that the total NOS activities (pmol citrulline/mg protein per min) using
$100 \mu \mathrm{M}, 1 \mathrm{mM}$ and $2 \mathrm{mM}$ L-NA were $136 \pm 4,139 \pm 4$ and $135 \pm 3$ respectively and did not significantly differ from each other.

\section{Vascular functions}

Thoracic aortas were isolated and placed in oxygenated $\left(95 \% \mathrm{O}_{2}\right.$ and $5 \% \mathrm{CO}_{2}$ ) Krebs buffer ( $\left.\mathrm{pH} 7 \cdot 4\right)$ of the following composition (mM): $\mathrm{NaCl} 117, \mathrm{KCl} 4 \cdot 7, \mathrm{CaCl}_{2}$ $2 \cdot 5, \mathrm{MgSO}_{4} 1 \cdot 18, \mathrm{KH}_{2} \mathrm{PO}_{4} 1 \cdot 2, \mathrm{NaHCO}_{3} 25$, dextrose 11 and EDTA 0.03 (Chemtob et al. 1992). The buffer was gassed with a mixture of $95 \% \mathrm{O}_{2}$ and $5 \% \mathrm{CO}_{2}$. Four rings (approximately $4 \mathrm{~mm}$ long and $1.5-2 \mathrm{~mm}$ diameter) from each aorta were set up in $25 \mathrm{ml}$ organ baths at $37^{\circ} \mathrm{C}$ at an applied tension of approximately $2 \mathrm{~g}$, which was monitored on a Grass polygraph by Grass force-displacement transducers (FT037) (Quincy). The endothelium was preserved in two rings and removed from two rings. Preparations were allowed to equilibrate for $1 \mathrm{~h}$ with changes in Krebs buffer every $15 \mathrm{~min}$. Following stabilization, two endothelium-intact rings and one endothelium-denuded ring were contracted with 100$300 \mathrm{nM}$ phenylephrine (producing approximately 75\% of the maximal contraction); concentration-relaxation response curves to $\mathrm{ACh}$ were determined in duplicate on the two endothelium-intact rings and to SNP on the one endothelium-denuded ring. One endothelium-denuded ring was used to construct concentration-contraction response curves to phenylephrine. $\mathrm{EC}_{50}$ values of these three agents were derived from the regression line of $\log$ molar concentration-percentage response curves.

\section{Statistics}

Data means were analysed by one-way ANOVA followed by Benferroni test for significance. A probability of $<0 \cdot 05$ was assumed to denote a significant difference. Data are presented as means \pm S.E.M.

\section{Results}

\section{General effects of streptozotocin diabetes}

Effects of diabetes of 14-15 days duration on different variables are presented in Table 1. Diabetes was associated with a decrease in body weight and an increase in kidney weight and plasma glucose. Basal values of urinary volume (UV), GFR, RPF, FF and plasma $\mathrm{NO}_{2}{ }^{-} / \mathrm{NO}_{3}{ }^{-}$were higher in diabetic than in control animals and higher in pregnant diabetic than in virgin diabetic rats. The mean arterial pressure (MAP) was lower in pregnant than in virgin rats. Diabetes led to a significant increase in urinary albumin and creatinine excretion but these variables did not differ between virgin and pregnant rats (Table 1). Diabetes of a shorter duration (7 days) also decreased body 
Table 1 Different variables in virgin control (VC), virgin diabetic (VD), pregnant control (PC) and pregnant diabetic (PD) rats 14-15 days following injection of streptozotocin or the vehicle. Data are means \pm S.E.M. of 7-9 experiments

\begin{tabular}{|c|c|c|c|c|}
\hline & VC & VD & PC & PD \\
\hline \multicolumn{5}{|l|}{ Variables } \\
\hline Body weight (g) & $253 \pm 10$ & $234 \pm 4^{a, b}$ & $285 \pm 6$ & $263 \pm 5^{a}$ \\
\hline Kidney weight (g) & $2 \cdot 1 \pm 0 \cdot 1$ & $3 \cdot 0 \pm 0 \cdot 2^{a, b}$ & $2 \cdot 2 \pm 0 \cdot 1$ & $2 \cdot 9 \pm 0 \cdot 1^{\mathrm{a}}$ \\
\hline Plasma glucose $(\mathrm{mmol} / \mathrm{l})$ & $7 \cdot 4 \pm 1 \cdot 3$ & $37 \pm 3 \cdot 1^{a, b}$ & $7 \cdot 8 \pm 1 \cdot 3$ & $35 \cdot 3 \pm 2 \cdot 9^{a}$ \\
\hline Placental weight (mg) & - & - & $450 \pm 13$ & $516 \pm 16^{\mathrm{a}}$ \\
\hline Mean arerial pressure $(\mathrm{mmHg})$ & $122 \pm 2$ & $114 \pm 3^{a, b}$ & $104 \pm 2^{d}$ & $106 \pm 2^{b, d}$ \\
\hline Renal plasma flow (ml/kg per min) & $10 \cdot 8 \pm 0 \cdot 8$ & $15 \cdot 8 \pm 0 \cdot 9^{a, c}$ & $13 \cdot 1 \pm 0 \cdot 3^{d}$ & $25 \cdot 1 \pm 1 \cdot 6^{\mathrm{a}, \mathrm{d}}$ \\
\hline Glomerular filtration rate $(\mathrm{ml} / \mathrm{kg}$ per $\mathrm{min})$ & $2 \cdot 6 \pm 0 \cdot 35$ & $7 \cdot 1 \pm 0 \cdot 11^{\mathrm{a}, \mathrm{b}}$ & $4 \cdot 3 \pm 0 \cdot 20^{d}$ & $8 \cdot 9 \pm 0 \cdot 31^{\mathrm{a}, \mathrm{d}}$ \\
\hline Filtration fraction & $0 \cdot 23 \pm 0 \cdot 03$ & $0 \cdot 45 \pm 0 \cdot 02^{a, b}$ & $0 \cdot 30 \pm 0 \cdot 02$ & $0 \cdot 38 \pm 0.01^{a, d}$ \\
\hline Plasma $\mathrm{NO}_{2}{ }^{-} / \mathrm{NO}_{3}{ }^{-}(\mu \mathrm{mol} / \mathrm{l})$ & $243 \pm 10$ & $720 \pm 50^{\mathrm{a}, \mathrm{c}}$ & $600 \pm 40^{\mathrm{d}}$ & $1930 \pm 230^{\mathrm{a}, \mathrm{d}}$ \\
\hline Urinary volume $(\mu \mathrm{l} / \mathrm{min}$ per $\mathrm{kg})$ & $21 \pm 5$ & $112 \pm 39^{\mathrm{a}, \mathrm{b}}$ & $44 \pm 9^{d}$ & $124 \pm 32^{\mathrm{a}, \mathrm{d}}$ \\
\hline Urinary $\mathrm{Na}^{+}(\mu \mathrm{mol} / \mathrm{kg}$ per min) & $0 \cdot 76 \pm 0 \cdot 21$ & $12 \cdot 8 \pm 1 \cdot 1^{\mathrm{a}, \mathrm{b}}$ & $0 \cdot 56 \pm 0 \cdot 18$ & $11 \cdot 6 \pm 1 \cdot 8^{\mathrm{a}, \mathrm{d}}$ \\
\hline Urinary albumin ( $\mathrm{ng} / \mathrm{min}$ per $\mathrm{kg}$ ) & $130 \pm 20$ & $1220 \pm 160^{\mathrm{a}, \mathrm{b}}$ & $220 \pm 80$ & $1225 \pm 150^{\mathrm{a}, \mathrm{d}}$ \\
\hline Urinary creatinine $(\mathrm{nmol} / \mathrm{min}$ per $\mathrm{kg})$ & $106 \pm 23$ & $214 \pm 46^{\mathrm{a}}$ & $170 \pm 32$ & $236 \pm 37^{\mathrm{a}, \mathrm{d}}$ \\
\hline
\end{tabular}

${ }^{a}$ Different $(P<0 \cdot 05)$ from the corresponding controls; ${ }^{b}$ different $(P<0.05)$ from the corresponding values for PC; ${ }^{c}$ different $(P<0 \cdot 05)$ from the corresponding value for $\mathrm{PD}$; ${ }^{\mathrm{d}}$ different $(P<0 \cdot 05)$ from the corresponding values for $\mathrm{VC}$ rats (ANOVA).

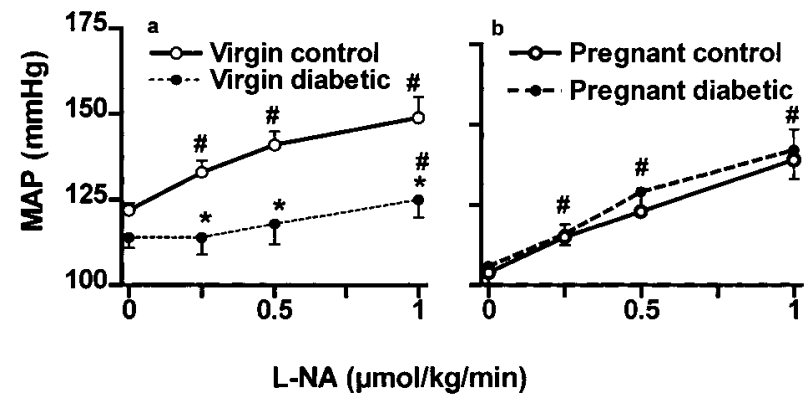

Figure 1 Effects of L-NA on MAP of nondiabetic and diabetic virgin (a) and $14-15$ days pregnant (b) rats. *Different $(P<0 \cdot 05)$ from the corresponding values in control rats; effects of L-NA were significant at all doses in virgin and pregnant control and pregnant diabetic rats but only at $1 \mu \mathrm{mol} / \mathrm{kg}$ per min in virgin diabetic rats. *Different $(P<0 \cdot 05)$ from the corresponding values for the nondiabetic controls. \#Different $(P<0 \cdot 05)$ from the basal values for the same group of rats. Data are means \pm S.E.M. of seven or eight experiments.

weight and increased plasma glucose and urine output; body weights $(\mathrm{g})$, plasma glucose $(\mathrm{mmol} / \mathrm{l})$ and $\mathrm{UV}(\mu \mathrm{l} / \mathrm{kg}$ per min) were respectively: $259 \pm 7,6 \cdot 8 \pm 0 \cdot 3$ and $19 \pm 6$ for virgin controls $(n=7) ; 243 \pm 4,34 \cdot 9 \pm 3$ and $126 \pm 12$ for virgin diabetic rats $(n=6) ; 270 \pm 2,7 \cdot 3 \pm 0 \cdot 6$ and $31 \pm 9$ for control pregnant rats $(n=6)$; and $240 \pm 2$, $22 \cdot 7 \pm 1 \cdot 3$ and $136 \pm 11$ for diabetic pregnant rats $(n=5)$.

Effects of $L-N A$ on renal haemodynamics 14-15 days after induction of diabetes

L-NA caused a dose-dependent increase in MAP in all groups of rats; the relative increases in MAP in virgin diabetic rats was less than in the other three groups of rats (Fig. 1a and b). L-NA did not exert a significant effect on GFR in virgin control rats but caused a dose-dependent decrease in GFR in pregnant controls and in both virgin

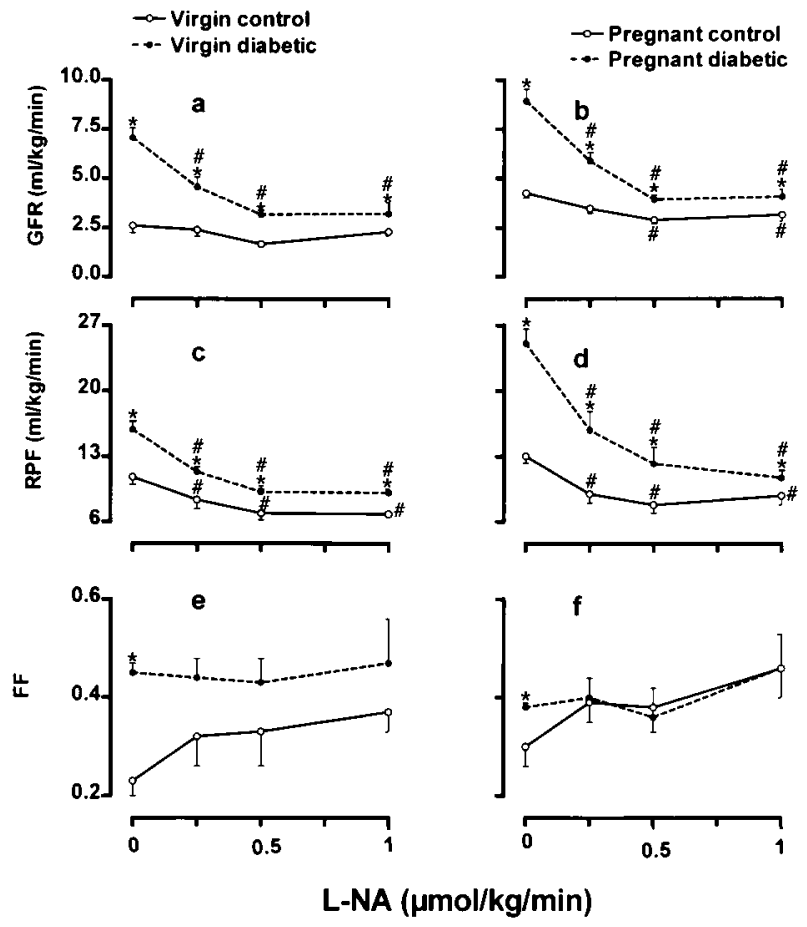

Figure 2 Effects of L-NA on GFR, RPF and FF of nondiabetic and diabetic virgin (a, c and e) and 14-15 days pregnant ( $b, d$ and $f$ ) rats. *Different $(P<0.05)$ from the corresponding values for the nondiabetic controls. \#Different $(P<0 \cdot 05)$ from the basal values in the same group of rats. Data are means \pm S.E.M. of seven or eight experiments.

and pregnant diabetic rats. The L-NA-induced decrease in GFR was greater in diabetic rats than in nondiabetic animals (Fig. $2 \mathrm{a}$ and b). Infusion of L-NA caused a dose-dependent decrease in RPF in all groups of rats; the effect was more marked in the diabetic than in control 


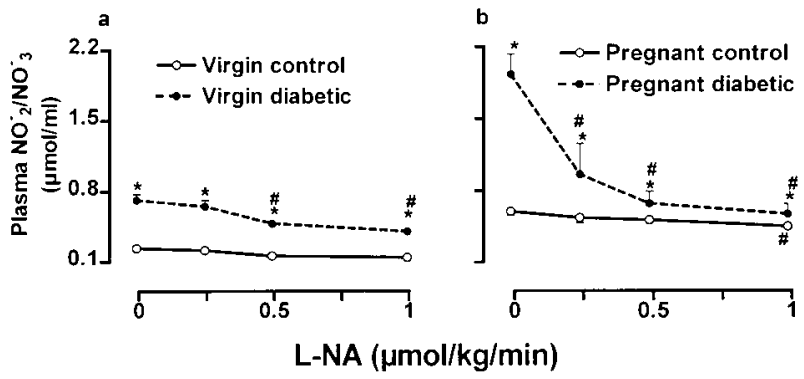

Figure 3 Effects of L-NA on plasma $\mathrm{NO}_{2}{ }^{-} / \mathrm{NO}_{3}{ }^{-}$in nondiabetic and diabetic virgin (a) and 14-15 days pregnant (b) rats. *Different $(P<0 \cdot 05)$ from the corresponding values for the nondiabetic controls. \#Different $(P<0.05)$ from the basal values for the same group of rats. Data are means \pm S.E.M. of five or six experiments.

animals (Fig. $2 \mathrm{c}$ and d). The maximal decrease in RPF following L-NA infusion was $37 \pm 3 \%$ in virgin diabetic rats and significantly less than in pregnant diabetic animals $(64 \pm 4 \%)$. L-NA increased $\mathrm{FF}$ in control virgin rats but not in the other three groups of animals (Fig. 2e and f).

\section{$U V$ and sodium excretion}

Basal excretion of water and sodium was significantly greater in 14 days diabetic than in nondiabetic rats (Table 1). L-NA exerted dose-dependent antidiuretic and antinatriuretic effects in all groups of rats and the maximal decrease in both variables following $1 \mu \mathrm{mol} / \mathrm{kg}$ per min was approximately $50 \%$ of the basal (data not shown).

\section{Plasma $\mathrm{NO}_{2}{ }^{-} / \mathrm{NO}_{3}{ }^{-}$}

Diabetes of 2 weeks duration was associated with an increase in plasma $\mathrm{NO}_{2}{ }^{-} / \mathrm{NO}_{3}{ }^{-}$. Infusion of $\mathrm{L}-\mathrm{NA}$ did not exert a significant effect on plasma $\mathrm{NO}_{2}{ }^{-} / \mathrm{NO}_{3}{ }^{-}$of nondiabetic virgin rats (Fig. 3a); the effect in control pregnant rats (Fig. 3b) was observed only at the highest dose of L-NA $(1 \mu \mathrm{mol} / \mathrm{kg}$ per min) studied. In contrast to nondiabetic rats, all doses of L-NA caused a dosedependent reduction in plasma $\mathrm{NO}_{2}{ }^{-} / \mathrm{NO}_{3}{ }^{-}$in both virgin and pregnant diabetic rats (Fig. $3 \mathrm{a}$ and $\mathrm{b}$ ); these effects were significantly greater in pregnant diabetic than in virgin diabetic animals.

\section{NOS activity}

Diabetes of 14 days duration led to an increase in calcium-dependent NOS activity in the kidney, heart, aorta and uterus of both virgin and pregnant rats; the placental NOS activity was not modified by diabetes (Table 2). Diabetes also led to an increase in total NOS activity in the heart, aorta and uterus (data not shown).

\section{Effects of L-NA on renal haemodynamics 7 days after} induction of diabetes

The effects of diabetes of a shorter duration (7 days) in both virgin and pregnant rats (Fig. 4) were similar to those described above for diabetes of 14-15 days duration. L-NA at a dose of $0.5 \mu \mathrm{mol} / \mathrm{kg}$ per min (producing near maximal effects in diabetic rats of 14-15 days duration) caused a significant increase in MAP (Fig. 4a) in all the four groups of rats but the increase was less in virgin diabetic rats than in the other three groups of animals. L-NA caused a decrease in GFR in virgin diabetic, control pregnant and diabetic pregnant rats but not in control virgin rats (Fig. $4 b)$. L-NA decreased RPF in all the four groups of rats (Fig. 4c) but increased FF only in control virgin rats (Fig. 4d).

\section{Vascular responses}

The maximal endothelium-dependent vasorelaxant effects of ACh (\% of phenylephrine-induced tone) on aortic rings from virgin control, virgin diabetic, pregnant control and pregnant diabetic rats were $90 \pm 3 \%(n=7), 85 \pm 3 \%$ $(n=6), 89 \pm 4 \%(n=5)$ and $80 \pm 6 \%(n=5)$ respectively and did not significantly differ from each other. ACh was a more potent relaxant on rings from diabetic virgin and pregnant rats than on preparations from nondiabetic

Table 2 Calcium-dependent NOS activity $\left(\mathrm{Ca}^{2+}\right.$-dependent $\left[{ }^{3} \mathrm{H}\right]$ citrulline production, $\mathrm{pmol} / \mathrm{mg}$ protein) in different tissues of virgin control (VC), virgin diabetic (VD), pregnant control (PC) and pregnant diabetic (PD) rats. The duration of pregnancy and diabetes at the time of tissue collections was $14-15$ days. Data are means \pm S.E.M. ( $n=5$ or 6$)$

\begin{tabular}{|c|c|c|c|c|}
\hline \multirow[b]{2}{*}{ Tissue } & \multirow[t]{2}{*}{ VC } & \multirow[t]{2}{*}{ VD } & \multirow[t]{2}{*}{ PC } & \multirow[t]{2}{*}{ PD } \\
\hline & & & & \\
\hline Kidney & $1 \cdot 79 \pm 0 \cdot 15$ & $2 \cdot 65 \pm 0 \cdot 17^{a}$ & $1 \cdot 84 \pm 0 \cdot 14$ & $2 \cdot 52 \pm 0 \cdot 16^{\mathrm{a}}$ \\
\hline Heart & $0.39 \pm 0.06$ & $0.98 \pm 0.08^{a}$ & $0.91 \pm 0.25^{b}$ & $2 \cdot 22 \pm 0 \cdot 15^{\mathrm{a}, \mathrm{c}}$ \\
\hline Aorta & $0 \cdot 91 \pm 0 \cdot 14$ & $2 \cdot 73 \pm 0 \cdot 05^{a}$ & $1 \cdot 22 \pm 0 \cdot 22$ & $3 \cdot 85 \pm 0 \cdot 17^{\mathrm{a}, \mathrm{c}}$ \\
\hline Uterus & $0 \cdot 80 \pm 0 \cdot 10$ & $2 \cdot 63 \pm 0 \cdot 19^{a}$ & $1 \cdot 58 \pm 0 \cdot 12^{\mathrm{b}}$ & $2 \cdot 71 \pm 0 \cdot 14^{\mathrm{a}}$ \\
\hline Placenta & - & - & $2 \cdot 25 \pm 0 \cdot 17$ & $2 \cdot 95 \pm 0 \cdot 19$ \\
\hline
\end{tabular}

${ }^{\text {a Different }}(P<0 \cdot 05)$ from the corresponding controls; ${ }^{b}$ different $(P<0 \cdot 05)$ from the corresponding virgin controls; ${ }^{c}$ different $(P<0 \cdot 05)$ from the corresponding virgin diabetic rats (ANOVA). 


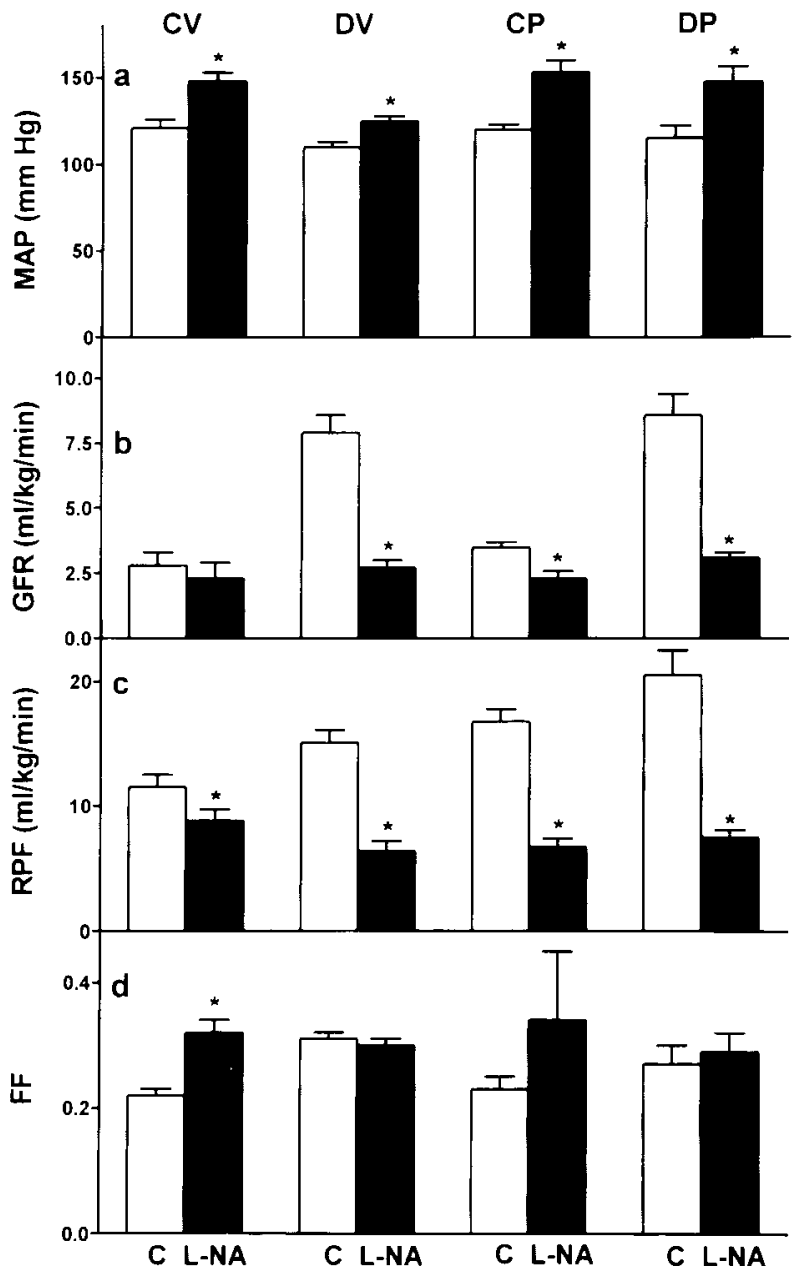

Figure 4 Effects of L-NA at a dose of $0.5 \mu \mathrm{mol} / \mathrm{kg}$ per min on the MAP, GFR, RPF and FF of control virgin (CV), 7 days diabetic virgin (DV), control pregnant (CP) and 7 days diabetic pregnant (DP) rats. Data are means \pm S.E.M. of five to seven experiments. *Different $(P<0.05)$ from the corresponding values in the control period before starting the infusion of L-NA.

animals; vasorelaxant $\mathrm{EC}_{50}$ of $\mathrm{ACh}$ on rings from control virgin, diabetic virgin, control pregnant and diabetic pregnant rats $(n=5-7)$ were $130 \pm 28 \mathrm{nM}, 37 \pm 8 \mathrm{nM}$, $140 \pm 33 \mathrm{nM}$ and $44 \pm 8 \mathrm{nM}$ respectively. NO donor SNP caused $100 \%$ relaxation of all preparations and there was no difference in its vasorelaxant potency on aortic rings from the four groups of rats (Fig. $5 c$ and d). The maximal phenylephrine-induced increases in the tone of aortic rings from virgin control, virgin diabetic, pregnant control and pregnant diabetic rats $(n=5-7)$ were $1002 \pm 98 \mathrm{mg}, 1150 \pm 20 \mathrm{mg}, 1170 \pm 225 \mathrm{mg}$ and $970 \pm 42 \mathrm{mg}$ respectively and did not differ significantly from each other; as well, there was no difference in the vasoconstrictor potency of phenylephrine on the preparations from the four groups of rats (Fig. 5e and f).

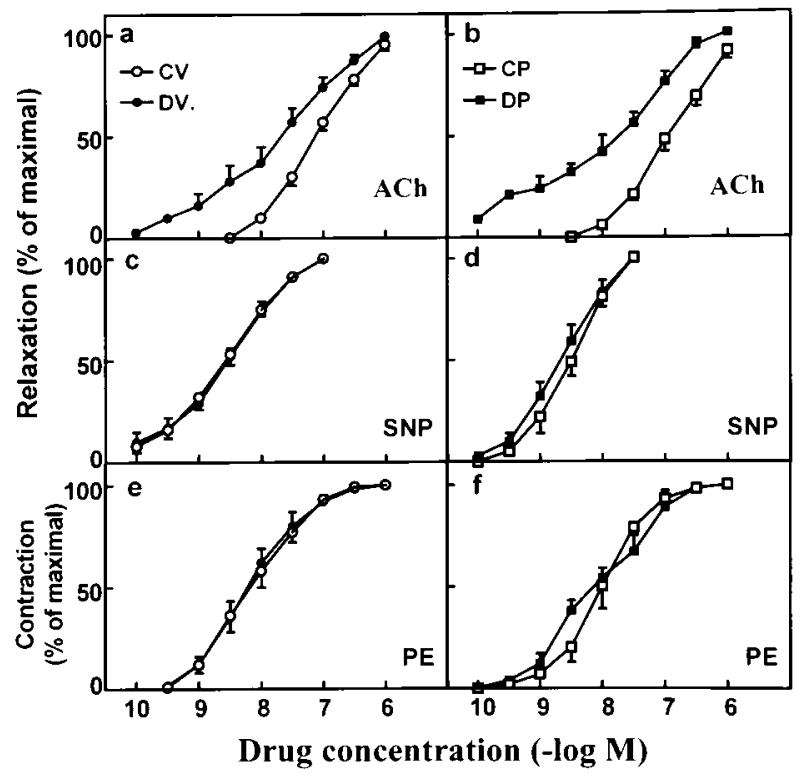

Figure 5 Concentration-response curves to ACh, SNP and phenylephrine (PE) on rings of thoracic aorta from control virgin $(\mathrm{CV})$, diabetic virgin (DV), control pregnant (CP) and diabetic pregnant (DP) rats. The duration of diabetes and pregnancy was 14-15 days. Data are means \pm S.E.M. of five or six aortic rings from separate animals.

\section{Discussion}

NO modulates renal haemodynamics (Tolins et al. 1990, Danielson \& Conrad 1995) and contributes to the renal hyperfiltration during diabetes (Bank \& Aynedjian 1993, Tolins et al. 1993, Komers et al. 1994). The renal complications of diabetes are worsened by pregnancy (Kitzmiller \& Combs 1996). The present studies were therefore done to determine if the role of NO in diabetesassociated renal hyperfiltration is altered by pregnancy. For this purpose we used both virgin and pregnant diabetic rats as the model and the role of $\mathrm{NO}$ in hyperfiltration was assessed using L-NA, which is an effective inhibitor of NOS (Mulsch \& Busse 1990, Moncada et al. 1991, Hardy et al. 1996).

In conformity with other data (Bank \& Aynedjian 1993, Tolins et al. 1993, Komers et al. 1994), diabetes of both 1 and 2 weeks duration produced hyperfiltration, which was virtually abolished by L-NA. However, L-NA was much less effective in increasing MAP in virgin diabetic rats than in control virgin animals (Figs $1 \mathrm{a}$ and $5 \mathrm{a}$ ). Although a decrease in the pressor response to NOS inhibitors in male rats has previously been reported by other workers (Kiff et al. 1991, Bank \& Aynedjian 1993, Komers et al. 1994), the reason for a decrease in the hypertensive effect of L-NA in virgin but not in pregnant diabetic rats observed in the present study (Figs 1b and 4a) is not clear; this could be caused by several factors including a heterogeneity in 
the role of $\mathrm{NO}$ in modulating the tone of different vascular beds (Kiff et al. 1991). An overall decrease in the role of NO in resistance vessels during diabetes (Poston \& Taylor 1995) could explain the relatively poor hypertensive response to L-NA in virgin diabetic animals; this inference implies that somehow hormonal changes accompanying pregnancy tend to alter the role of $\mathrm{NO}$, for which there is some evidence in the literature (Moroi et al. 1998).

Several studies have reported that the inhibition of NO synthesis ameliorates the diabetes-associated increase in GFR and RPF (Bank \& Aynedjian 1993, Tolins et al. 1993, Komers et al. 1994); this inference is supported by our data that the renal haemodynamic responses to the inhibition of $\mathrm{NO}$ synthesis by L-NA were more marked in both 7 days and 14-15 days diabetic (Figs 2 and 4) than in nondiabetic rats. Indeed the effects of the low dose of L-NA $(0.25 \mu \mathrm{mol} / \mathrm{kg}$ per min) on GFR was apparent only in diabetic animals (Fig. 2a) as has been previously reported (Komers et al. 1994), although higher doses caused a small but significant decrease in GFR in control pregnant rats (Figs $2 \mathrm{~b}$ and $4 \mathrm{~b}$ ). Other workers also found that relatively low doses of L-NAME $(2 \mu \mathrm{g} / \mathrm{min}$ per rat) and L-NMMA $(100 \mu \mathrm{g} / \mathrm{min}$ per rat) did not reduce GFR in conscious virgin rats although a significant decrease in GFR was observed in pregnant rats (Danielson \& Conrad 1995). On the other hand, a bolus high dose of $10 \mathrm{mg} / \mathrm{kg}$ (approximately $35 \mu \mathrm{mol} / \mathrm{kg}$ ) of L-NAME was found to reduce GFR in conscious virgin rats (Baylis et al. 1990, 1993). It would thus seem that the ineffectiveness of L-NA to reduce GFR in virgin controls and do so only at relatively high doses in control pregnant (both 7 and 14-15 days) rats, reflects differences in experimental conditions and doses of NOS blockers between the present study using urethane-anaesthetized rats and conscious rats used by others (Baylis et al. 1990, 1993, Danielson \& Conrad 1995).

In contrast to effects in nondiabetic animals discussed above, both low and high doses of L-NA markedly decreased GFR in animals diabetic for 14-15 days (Fig. 2a and b) or 7 days (Fig. 4b). L-NA decreased RPF in all groups of rats although the magnitude of this effect was significantly greater in diabetic than in nondiabetic rats (Fig. 2). These data suggest that NO might play a greater role in modulating RPF than GFR. L-NA-induced increase in FF in nondiabetic but not in diabetic rats might be because of disproportionate changes in GFR and RPF and because of high basal values of FF in diabetic animals (Fig. 2e and f). Overall the effects of L-NA on renal haemodynamics are strongly suggestive of a role for increased NO synthesis in hyperfiltration associated with diabetes. Since the overall renal haemodynamic effects of L-NA were greater in diabetic pregnant than in diabetic virgin rats, it would appear that the contribution of $\mathrm{NO}$ in renal hyperfiltration was augmented by pregnancy. An increase in $\mathrm{NO}$ synthesis as reflected by high plasma $\mathrm{NO}_{2}{ }^{-} / \mathrm{NO}_{3}{ }^{-}$levels and tissue (kidney, heart, aorta)
NOS activity during diabetic pregnancy (Table 1) is in accordance with this suggestion.

Diabetes increased basal urinary flow and sodium excretion rates (Table 1) in conformity with other reports (Komers et al. 1994). L-NA exerted antinatriuretic and antidiuretic effects in all groups of animals; these data are consistent with the observed decrease in GFR, although our data do not exclude the possibility of effects of $\mathrm{NO}$ on other segments of the nephron. We did not observe any pressure natriuresis as reported by others (Johnson \& Freeman 1992, Komers et al. 1994). This discrepancy between our findings and those of others (Komers et al. 1994) could be related to the dose and method of administration of L-NA; we administered lower doses $(0 \cdot 25-1 \mu \mathrm{mol} / \mathrm{kg}$ per min) of L-NA by continuous infusion compared with a bolus dose of $37 \mu \mathrm{mol} / \mathrm{kg}$ L-NAME used by others (Komers et al. 1994).

We found that 2 weeks of diabetes slightly but significantly increased the endothelium-dependent vasorelaxant effect of ACh but did not modify responses to SNP and phenylephrine (Fig. 5). A lack of change in the vasorelaxant effect of NO donor SNP and the vasoconstrictor effect of phenylephrine is in conformity with other reports (Durante et al. 1988); these data suggest that the vascular reactivity is not modified by diabetes of 2 weeks duration. However, the increase in vasorelaxant potency of ACh on aortic rings from diabetic rats is at variance with the generally observed dysfunction of endothelial cells in diabetes of relatively long duration (Poston \& Taylor 1995, Sobrevia \& Mann 1997); the most likely explanation for this discrepancy appears to be the duration of diabetes. Of particular relevance to the present study is the report that diabetes of 12 days duration increased the vasodilator effects of ACh on renal vessels (Bhardwaj \& Moore 1988). It is very likely that increased NO release during early stages of diabetes contributes to endothelial dysfunction with the progression of the diabetic state.

Our experimental protocol does not permit any definitive conclusion regarding the source of the increased role of $\mathrm{NO}$ in renal haemodynamics during diabetes and diabetic pregnancy. The assay of NOS activity in different tissues suggests that several organs might contribute to the increase in plasma NO during diabetes. For example, NOS activity was greater in the kidneys, hearts, aortas and uteri of the diabetic than of nondiabetic rats and greater in pregnant diabetic than in virgin diabetic animals (Table 2).

It has been suggested that increased synthesis of $\mathrm{NO}$ by vascular beds and the placenta contributes to the elevated plasma levels and urinary excretion of $\mathrm{NO}_{2}{ }^{-} / \mathrm{NO}_{3}{ }^{-}$ during normal pregnancy (Conrad et al. 1993, McLaughlin \& Conrad 1995). Current data suggest that peripheral vasodilatation during pregnancy largely results from endothelial NO (Deng et al. 1996, Hines \& Mifflin 1997) and pregnancy is associated with increased expression of endothelial NOS in the rat aorta (Goetz et al. 1994); in general our data support these inferences. However, a lack 
of difference in NOS activity in the placentas of diabetic and nondiabetic rats would suggest that the placenta is not the source of the observed increase in the role of NO in renal haemodynamics during diabetic pregnancy.

In summary, the findings of the present study support our hypothesis that the state of diabetes during pregnancy accentuates the role of $\mathrm{NO}$ in renal hyperfiltration.

\section{Acknowledgement}

This study was supported by a grant from the Kidney Foundation of Canada.

\section{References}

Bank N \& Aynedjian HS 1993 Role of EDRF (nitric oxide) in diabetic renal hyperfiltration. Kidney International 43 1306-1312.

Baylis C 1984 Renal hemodynamics and volume control during pregnancy in the rat. Seminars in Nephrology 4 208-220.

Baylis C \& Qiu C 1996 Importance of nitric oxide in the control of renal hemodynamics. Kidney International 49 1727-1731.

Baylis C, Harton P \& Engels K 1990 Endothelial derived relaxing factor (EDRF) controls renal hemodynamics in the normal rat kidney. Journal of the American Society of Nephrology 1 875-881.

Baylis C, Engels K, Samsell L \& Harton P 1993 Renal effects of acute endothelial-derived relaxing factor blockade are not mediated by angiotensin II. American Journal of Physiology 264 F74-F78.

Bhardwaj R \& Moore PK 1988 Increased vasodilator response to acetylcholine of renal blood vessels from diabetic rats. Journal of Pharmacy and Pharmacology 40 739-742.

Chemtob S, Inayatulla A \& Varma DR 1992 Eicosanoid-dependent and endothelium-independent oscillations of rat aorta. Journal of Vascular Research 29 270-280.

Chowdhury TA, Barnett AH \& Bain SC 1996 Pathogenesis of diabetic nephropathy. Trends in Endocrinology and Metabolism 7 320-323.

Conliffe PR, Santos GL, Varma DR \& Mulay S 1992 Cytotoxic factor in the serum of diabetic rats and its increase during pregnancy. Journal of Endocrinology 134 205-214.

Conrad KP, Joffe GM, Kruszyna H, Kruszyna R, Rochelle LG, Smith RP, Chavez JE \& Mosher MD 1993 Identification of increased nitric oxide biosynthesis during pregnancy in rats. FASEB Journal 7 566-571.

Danielson LA \& Conrad KP 1995 Acute blockade of nitric oxide synthase inhibits renal vasodilation and hyperfiltration during pregnancy in chronically catheterized conscious rats. Journal of Clinical Investigation 96 482-490.

Deng A, Engels K \& Baylis C 1996 Impact of nitric oxide deficiency on blood pressure and glomerular hemodynamic adaptations to pregnancy in the rat. Kidney International 50 1132-1138.

Durante W, Sen AK \& Sunahara FA 1988 Impairment of endothelium-dependent relaxation in aortae from spontaneously diabetic rats. British Journal of Pharmacology 94 463-468.

Furchgott RF 1983 Role of endothelium in responses of vascular smooth muscle. Circulation Research 53 557-573.

Furchgott RF \& Zawadzki JV 1980 The obligatory role of endothelial cells in the relaxation of arterial smooth muscle by acetylcholine. Nature 288 373-376.

Gallery EDM 1984 Volume homeostasis in normal and hypertensive human pregnancy. Seminars in Nephrology 4 221-231.

Goetz RM, Morano I, Calovini T, Studer R \& Holtz J 1994 Increased expression of endothelial constitutive nitric oxide synthase in rat aorta during pregnancy. Biochemical and Biophysical Research Communications 205 905-910.
Hardy P, Peri KG, Lahaie I, Varma DR \& Chemtob S 1996 Increased nitric oxide synthesis and action preclude choroidal vasoconstriction to hyperoxia in newborn pigs. Circulation Research 79 504-511.

Hicks RC, Moss J, Higman DJ, Greenhalgh RM \& Powell JT 1997 The influence of diabetes on the vasomotor responses of saphenous vein and the development of infra-inguinal vein graft stenosis. Diabetes 46 113-118.

Hines T \& Mifflin SW 1997 Nitric oxide mediation of cardiac receptor reflex responses in the pregnant rat. American Journal of Obstetrics and Gynecology 177 1502-1508.

Hostetter TH, Troy JL \& Brenner BM 1981 Glomerular hemodynamics in experimental diabetes mellitus. Kidney International 19 410-415.

Johnson RA \& Freeman RH 1992 Pressure natriuresis in rats during blockade of the L-arginine/nitric oxide pathway. Hypertension 19 333-338.

Kiff RJ, Gardiner SM, Compton AM \& Bennett T 1991 The effects of endothelin-1 and $\mathrm{N}^{\mathrm{G}}$-nitro-L-arginine methyl ester on regional haemodynamics in conscious rats with streptozotocin-induced diabetes mellitus. British Journal of Pharmacology 103 1321-1326.

Kitzmiller JL \& Combs CA 1996 Diabetic nephropathy and pregnancy. Obstetrics and Gynecology Clinics of North America 23 173-203.

Komers R, Allen TJ \& Cooper ME 1994 Role of endotheliumderived nitric oxide in the pathogenesis of renal hemodynamic changes of experimental diabetes. Diabetes 43 1190-1197.

McLaughlin MK \& Conrad KP 1995 Nitric oxide biosynthesis during pregnancy: implications for circulatory changes. Clinical and Experimental Pharmacology and Physiology 22 164-171.

Moncada S, Palmer RMJ \& Higgs EA 1991 Nitric oxide: physiology, pathophysiology, and pharmacology. Pharmacological Reviews $\mathbf{4 3}$ 109-142.

Moroi M, Zhang L, Yasuda T, Virmani R, Gold HK, Fishman MC \& Huang PL 1998 Interaction of genetic deficiency of endothelial nitric oxide, gender, and pregnancy in vascular response to injury in mice. Journal of Clinical Investigation 101 1225-1232.

Moshage H, Kok B, Huizenga JR \& Jansen PLM 1995 Nitrite and nitrate determinations in plasma: a critical evaluation. Clinical Chemistry 41 892-896.

Mulsch A \& Busse R $1990 \mathrm{~N}^{\mathrm{G}}$-nitro-L-arginine $\left(\mathrm{N}^{5}\right.$ (imino(nitroamino)methyl)-L-ornithine) impairs endotheliumdependent dilations by inhibiting cytosolic nitric oxide synthesis from L-arginine. Naunyn-Schmiedebergs Archives of Pharmacology 341 143-147.

Omer S, Mulay S, Cernacek P \& Varma DR 1995 Attenuation of renal effects of atrial natriuretic factor during rat pregnancy. American Journal of Physiology 268 F416-F422.

Palmer RMJ, Ferrige AG \& Moncada S 1987 Nitric oxide release accounts for the biological activity of endothelium-derived relaxing factor. Nature 327 524-526.

Poston L \& Taylor PD 1995 Endothelium-mediated vascular function in insulin-dependent diabetes mellitus. Clinical Science 88 245-255.

Raij L 1993 Nitric oxide and the kidney. Circulation 87 V26-V29.

Rudberg S, Persson B \& Dahlquist G 1992 Increased glomerular filtration rate as a predictor of diabetic nephropathy - an 8-year prospective study. Kidney International 41 822-828.

Salter M, Knowles RG \& Moncada S 1991 Widespread tissue distribution, species distribution and changes in activity of $\mathrm{Ca}^{2+}$-dependent and $\mathrm{Ca}^{2+}$-independent nitric oxide synthases. FEBS Letters 291 145-149.

Shultz PJ, Schorer AE \& Raij L 1990 Effects of endothelium-derived relaxing factor and nitric oxide on rat mesangial cells. American Journal of Physiology 258 F162-F167.

Sobrevia L \& Mann GE 1997 Dysfunction of the endothelial nitric oxide signalling pathway in diabetes and hyperglycaemia. Experimental Physiology 82 423-452. 
Tolins JP, Palmer RMJ, Moncada S \& Raij L 1990 Role of endothelium-derived nitric oxide in regulation of renal hemodynamic responses. American Journal of Physiology 258 H655-H662.

Tolins JP, Shultz PJ, Raij L, Brown DM \& Mauer SM 1993 Abnormal renal hemodynamic responses to reduced renal perfusion pressure in diabetic rats: role of NO. American Journal of Physiology 265 F886-F895.

Verdon CP, Burton BA \& Prior RL 1995 Sample pretreatment with nitrate reductase and glucose-6-phosphate dehydrogenase quantitatively reduces nitrate while avoiding interference by
$\mathrm{NADP}^{+}$when the Griess reaction is used to assay for nitrite. Analytical Biochemistry 224 502-508.

Veves A, Akbari CM, Primavera J, Donaghue VM, Zacharoulis D, Chrzan JS, DeGirolami U, LoGerfo FW \& Freeman R 1998 Endothelial dysfunction and the expression of endothelial nitric oxide synthase in diabetic neuropathy, vascular disease, and foot ulceration. Diabetes 47 457-463

Received 7 May 1998

Revised manuscript received 9 September 1998 Accepted 18 November 1998 